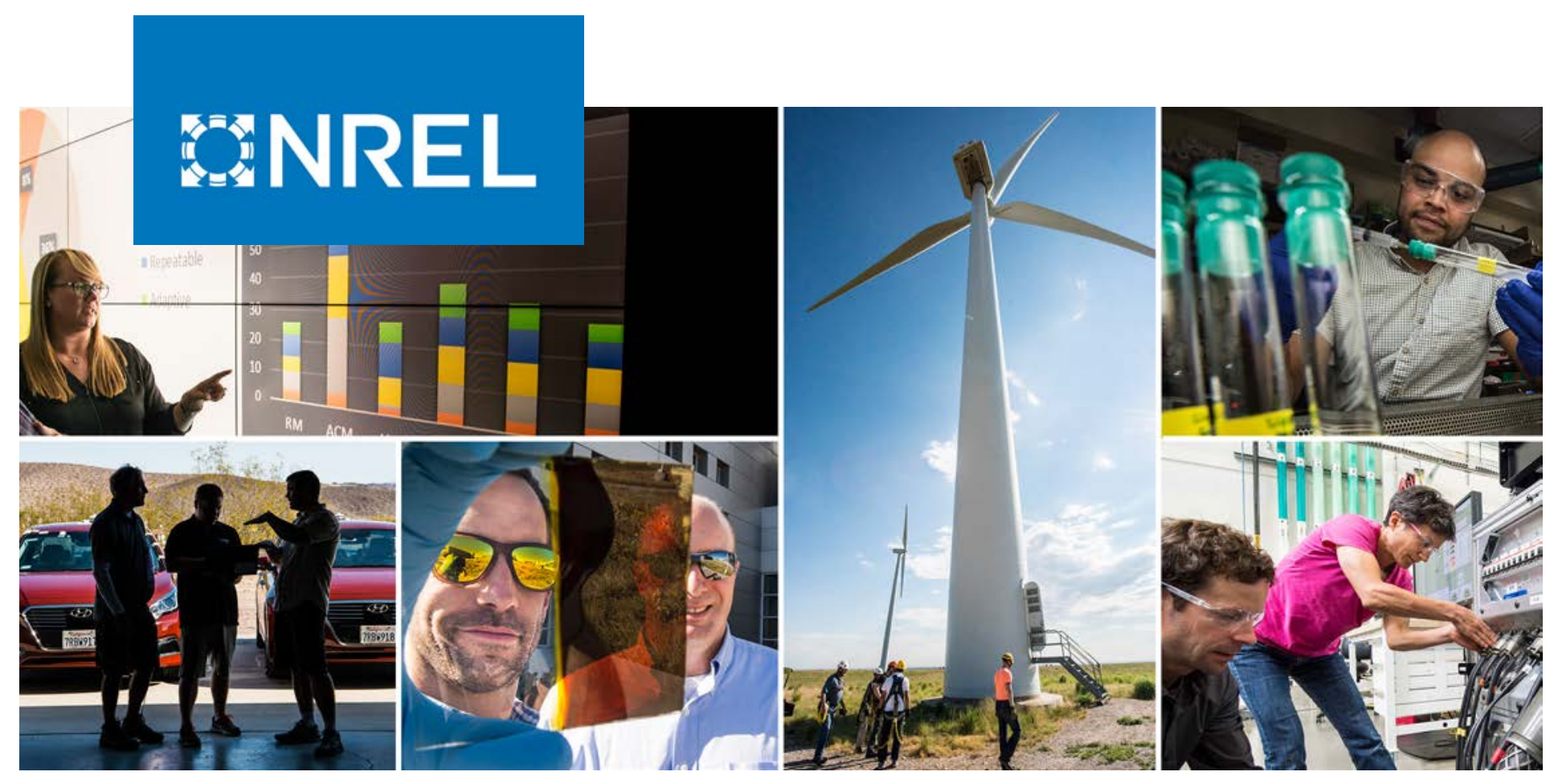

\title{
Quantifying Solar PV Variability at Multiple Timescales for Power Systems Studies
}

\section{Preprint}

Himanshu Jain, Manajit Sengupta, Aron Habte, and Jin Tan

National Renewable Energy Laboratory

Presented at the 47th IEEE Photovoltaic Specialists Conference (PVSC 47) June 15-August 21, 2020

NREL is a national laboratory of the U.S. Department of Energy Office of Energy Efficiency \& Renewable Energy

Operated by the Alliance for Sustainable Energy, LLC

This report is available at no cost from the National Renewable Energy Laboratory (NREL) at www.nrel.gov/publications.

\section{Conference Paper}

NREL/CP-5D00-75869

June 2020 


\title{
GNREL
}

\section{Quantifying Solar PV Variability at Multiple Timescales for Power Systems Studies}

\section{Preprint}

\author{
Himanshu Jain, Manajit Sengupta, Aron Habte, \\ and Jin Tan \\ National Renewable Energy Laboratory
}

\section{Suggested Citation}

Jain, Himanshu, Aron Habte, Manajit Sengupta, and Jin Tan. 2020. Quantifying Solar PV

Variability at Multiple Timescales for Power Systems Studies: Preprint. Golden, CO:

National Renewable Energy Laboratory. NREL/CP-5D00-75869.

https://www.nrel.gov/docs/fy20osti/75869.pdf.

\begin{abstract}
(C) 2020 IEEE. Personal use of this material is permitted. Permission from IEEE must be obtained for all other uses, in any current or future media, including reprinting/republishing this material for advertising or promotional purposes, creating new collective works, for resale or redistribution to servers or lists, or reuse of any copyrighted component of this work in other works.
\end{abstract}

NREL is a national laboratory of the U.S. Department of Energy Office of Energy Efficiency \& Renewable Energy Operated by the Alliance for Sustainable Energy, LLC

This report is available at no cost from the National Renewable Energy Laboratory (NREL) at www.nrel.gov/publications.

Contract No. DE-AC36-08GO28308
Conference Paper

NREL/CP-5D00-75869

June 2020

National Renewable Energy Laboratory 15013 Denver West Parkway Golden, CO 80401

303-275-3000 • www.nrel.gov 


\section{NOTICE}

This work was authored in part by the National Renewable Energy Laboratory, operated by Alliance for Sustainable Energy, LLC, for the U.S. Department of Energy (DOE) under Contract No. DE-AC36-08GO28308. Funding provided by U.S. Department of Energy Office of Energy Efficiency and Renewable Energy Solar Energy Technologies Office. The views expressed herein do not necessarily represent the views of the DOE or the U.S. Government.

This report is available at no cost from the National Renewable Energy Laboratory (NREL) at www.nrel.gov/publications.

U.S. Department of Energy (DOE) reports produced after 1991 and a growing number of pre-1991 documents are available free via www.OSTI.gov.

Cover Photos by Dennis Schroeder: (clockwise, left to right) NREL 51934, NREL 45897, NREL 42160, NREL 45891, NREL 48097, NREL 46526.

NREL prints on paper that contains recycled content. 


\title{
Quantifying Solar PV Variability at Multiple Timescales for Power Systems Studies
}

\author{
Himanshu Jain, Manajit Sengupta, Aron Habte and Jin Tan \\ National Renewable Energy Laboratory \\ Golden, Colorado, USA \\ Himanshu.Jain@nrel.gov; Manajit.Sengupta@nrel.gov; Aron.Habte@nrel.gov; Jin.Tan@nrel.gov
}

\begin{abstract}
This paper presents two metrics - Fourier coefficients of irradiation ramps and average irradiation ramps to quantify solar photovoltaic (PV) variability at multiple temporal scales to improve the accuracy of power systems studies under high solar PV penetrations. The key findings based on these metrics are: (i) a single sensor significantly exaggerates the variability of a solar $P V$ power plant at seconds to 1-minute temporal resolution, but it can be fairly accurate at lower than 1minute resolutions, (ii) at each 1-minute and lower temporal resolution, largest solar irradiation ramps appear to be independent of the geographical location, and (iii) significant reduction in solar PV plant variability over a region with multiple plants is possible at all temporal scales, but more high temporal resolution data is needed to conclusively quantify the reduction.
\end{abstract}

Keywords-solar photovoltaics, variability of solar PV power plant, multi-timescale, global horizontal irradiation, rotating shadowband radiometer

\section{INTRODUCTION}

Reliable operation of power systems requires that interactions among various devices and equipment and the grid are studied at multiple timescales (sub-seconds to several hours). Electromechanical transient programs can be used to study these interactions using validated models of various equipment and controllers. Models of conventional generators are standardized, and it is assumed in electromechanical transient simulations that enough fuel is available at all times to meet the power demand put on these generators by the rest of the system. This assumption, however, breaks down with solar PV (and other variable renewable energy resources such as wind), where the plant operator has no control over the incident solar irradiation. Therefore, modeling solar irradiation is critical to accurately simulating the input power to the solar panels and inverters.

The main challenge in modeling solar irradiation and the resulting output of solar PV plants arises from the variability induced by clouds. The analytical solution to modeling cloudsinduced irradiation variability is to use numerical weather prediction models such as WRF-solar [1]. However, developing models of solar irradiation and solar PV plant outputs at the temporal and spatial scales required in electromechanical transient simulations (sub-seconds to few minutes) is extremely computationally expensive and the data required to initialize the simulations is not publicly available today. The alternative is to use publicly available datasets to model the temporal and spatial variability, which is the approach that was adopted in this paper.

There have been several efforts in the past to quantify solar PV variability at various spatial and temporal scales [2]-[9]. The wide variety of approaches used in these studies points to the absence of a universally acceptable method of quantifying solar PV variability. From the point of view of power systems reliability, particularly for frequency response analysis, variabilities ranging from seconds to several minutes are of interest [10]. E.g., a single large-ramp during a day may be easier to manage than several large unexpected variations that occur throughout a day because reliability metrics such as the control performance standard (CPS) scores [11] may be more adversely impacted by the latter.

Therefore, in this paper we propose two metrics that enable solar PV variability to be captured across an entire day over timescales ranging from seconds to an hour. These metrics are (i) Fourier coefficients and (ii) average irradiation ramps. Data from NREL's Measurement and Instrumentation Data Center (MIDC) [12] for 6 locations across the US is used to compare the performance of the two metrics and quantify and analyze solar PV variability.

\section{Methodology to Calculate the Variability Metrics}

\section{A. Fourier Coefficients of Irradiation Spectrum}

Fourier coefficients are obtained by using discrete Fourier transform. Fourier transform is applied on an entire day's data resulting in a frequency resolution of $1 /\left(\mathrm{H}^{*} 3600\right) \mathrm{Hz}$, where " $\mathrm{H}$ " is the number of hours for which the data is collected during a day. The highest frequency that can be captured is "fs/2" Hz, where "fs" is the sampling frequency of the data set. E.g., if a dataset has 1-second resolution data, "fs" is $1 \mathrm{~Hz}$ and the minimum frequency that can be captured using the Fourier transform is $0.5 \mathrm{~Hz}$. In other words, the maximum temporal resolution of variability that can be quantified for 1-second resolution dataset using the Fourier coefficient metric is 2seconds.

\section{B. Average Irradiation Ramps}

The average irradiation ramp metric at a temporal resolution is obtained in three steps. Step 1. Obtain a series of averages of solar irradiation using (1) with the averaging interval equal to the desired temporal resolution (e.g., if a dataset has the highest resolution of 1-minute, and the desired temporal resolution is 5minutes, 5-point moving average is calculated). Step 2. Obtain a series of magnitudes of irradiation ramps using (2), which 
calculates the absolute value of the difference between two consecutive average irradiation values obtained in step 1. Step 3. Average irradiation ramp metric at the desired temporal resolution is obtained using (3) as the mean of the ramps calculated in step 2

$$
\begin{gathered}
\bar{x}_{\imath}=\frac{\left(\sum_{j=T *(i-1)+1}^{T * i} x_{j}\right)}{T} ; i=1,2, \ldots, M \\
r_{i}=\left|\overline{x_{\imath+1}}-\bar{x}_{\imath}\right| ; i=1,2, \ldots, M-1 \\
\text { average irradiation ramp metric }=\frac{\left(\sum_{i=1}^{M-1} r_{i}\right)}{M-1}
\end{gathered}
$$

Where, $M=$ floor $\left(\frac{L}{T}\right) ; x_{j}$ is the $j^{\text {th }}$ solar irradiation value; $L$ is the length of the solar irradiation data collected over a day; $T$ is the desired temporal resolution, which is always less than the temporal resolution of the solar irradiation data (e.g., if the irradiation data is collected at a resolution of 1-minute, $T$ cannot be less than 1-minute).

\section{ApllicAtion OF VARIABILITY Metrics}

Table I lists the six MIDC solar irradiation datasets whose variabilities were evaluated using the two metrics.

TABLE I. SIX MIDC DATASETS

\begin{tabular}{|c|c|c|c|c|c|}
\hline Station & State & $\begin{array}{c}\text { Latitude/ } \\
\text { Longitude }\end{array}$ & Resolution & $\begin{array}{c}\text { Dataset } \\
\text { Length }\end{array}$ & Sensors \\
\hline Oahu [13] & HI & $\begin{array}{c}21.31 \mathrm{~N} / \\
158.09 \mathrm{~W}\end{array}$ & 1 second & $\begin{array}{c}10 \\
\text { months }\end{array}$ & 17 \\
\hline $\begin{array}{c}\text { SolarTAC } \\
{[14]}\end{array}$ & CO & $\begin{array}{c}39.76 \mathrm{~N} / \\
104.62 \mathrm{~W}\end{array}$ & 1 minute & 1 year & 1 \\
\hline $\begin{array}{c}\text { NREL } \\
\text { Station } \\
{[15]}\end{array}$ & CO & $\begin{array}{c}39.74 \mathrm{~N} / \\
105.18 \mathrm{~W}\end{array}$ & 1 minute & 1 year & 1 \\
\hline $\begin{array}{c}\text { UNLV } \\
{[16]}\end{array}$ & NV & $\begin{array}{c}36.11 \mathrm{~N} / \\
115.14 \mathrm{~W}\end{array}$ & 1 minute & 1 year & 1 \\
\hline $\begin{array}{c}\text { UAT } \\
\text { (OASIS) } \\
{[17]}\end{array}$ & AZ & $\begin{array}{c}32.23 \mathrm{~N} / \\
110.96 \mathrm{~W}\end{array}$ & 1 minute & 1 year & 1 \\
\hline $\begin{array}{c}\text { UTPASRL } \\
{[18]}\end{array}$ & TX & $\begin{array}{c}26.31 \mathrm{~N} / \\
98.17 \mathrm{~W}\end{array}$ & 1 minute & 1 year & 1 \\
\hline
\end{tabular}

\section{A. Solar Variability Analysis Using The Oahu Dataset}

The Oahu dataset had the highest temporal resolution and it also had 17 sensors spread over an area of $1 \mathrm{sq}$. $\mathrm{km}$, which is why this dataset was first used to validate and compare the performance of the two metrics. Fourier coefficients were obtained at six temporal scales - 2, 10, 60, 300, 900, and 3,600 seconds and four spatial scales using the Global Horizontal Irradiance (GHI) of 1 sensor (AP3), average GHI of 4 sensors (DH6, 8, 10 and 11), average GHI of 9 sensors (DH2-7,9,10 and AP1), and the average GHI of all 17 sensors. Sensor layout is available in [19].

Fig. 1, Fig. 2 and Fig. 3 plot the Fourier coefficients from 1, 4, and 9 sensors against the Fourier coefficients of all 17 sensors, respectively. Table II and Table III list the highest and lowest variability days identified for the four sensor aggregations, respectively. Fig. 4 shows the average GHI of 17 sensors and the GHI of sensor AP3 for the maximum and minimum variability days listed in Table II and Table III for 2seconds and 5-minute resolutions.

Plots similar to those in Fig. 1, Fig. 2 and Fig. 3 for the average irradiation ramp metric are shown in Fig. 5, Fig. 6, and Fig. 7, respectively. The maximum and minimum variability days identified using the average ramp metric are shown in Table IV and Table V. Fig. 8 is the same plot as Fig. 4 but for the average ramp metric.

Key observations from these figures and tables are:

- Both metrics suggest that single sensor shows much larger variability at seconds-level temporal resolutions compared to that obtained using average of 4, 9 and 17 sensors, while variability obtained from all the sensors at 5-minutes and lower temporal resolutions are very similar. Significantly larger scale of the Y axis w.r.t to the $\mathrm{X}$ axis in Fig. 1, Fig. 2 and Fig. 3 and Fig. 5, Fig. 6, and Fig. 7 for seconds level variabilities support this observation. This suggests that correlation in solar irradiation at various locations in a large plant at higher temporal resolutions is lower and it increases as the temporal resolution reduces. In other words, secondslevel solar PV plant variability obtained from one sensor may significantly exaggerate its impact on the grid. These observations are also consistent with those made in [4].

- As the number of sensors used to estimate solar irradiation variability increases from 1 to 9 , the variability estimates become closer to those obtained from using all 17 sensors, particularly at 1 minute and lower temporal resolutions. Even the 2-seconds variability reduced significantly with 4 sensors. E.g., the maximum value of $\mathrm{Y}$-axis of the 2-seconds variability plot in Fig. 6 became $25 \mathrm{~W} / \mathrm{m}^{2}$ from $50 \mathrm{~W} / \mathrm{m}^{2}$ in Fig. 5 , which is much closer to the $15 \mathrm{~W} / \mathrm{m}^{2}$ maximum value of the $\mathrm{X}$ axis in these figures (which is the variability obtained from the average GHI of all 17 sensors). This observation suggests that if a dense array of sensors cannot be deployed at a location, a cluster of a few appropriately spaced sensors may give significantly better estimates of solar irradiation variabilities at high temporal resolutions than those obtained from a single sensor.

- Comparison of the relative performance of the two metrics suggests that ramp-based metric performs better than the Fourier coefficient metric. This can be observed from Table II and Table IV, where the total number of unique maximum variability days identified by the Fourier coefficient metric are 14, compared to 10 from the average ramp metric. The total number of unique minimum variability days identified by the Fourier coefficient metric are 7 (Table III) compared to 2 identified by the ramp metric (Table V). This indicates more consistent identification of maximum and minimum variability days across temporal and spatial scales by the average ramp metric. Moreover, comparison of Fig. 4 and Fig. 8 provides visual verification of the better performance of the average 
ramp metric at higher temporal resolutions because the difference between maximum and minimum variability days is significantly clearer for the average ramp metric (Fig. 6) than for the Fourier coefficient metric (Fig. 3), for 2-seconds variability. The considerably poor performance of the Fourier coefficient metric in characterizing the 2-seconds variability is likely due to noise in Fourier analysis that distorted the actual $0.5 \mathrm{~Hz}$ component, which is the highest frequency that can be obtained in the 1-second dataset. It is likely that samples taken at higher resolution than $1 \mathrm{~Hz}$ can improve the performance of the Fourier analysis-based metric in identifying the variability at such high resolutions.
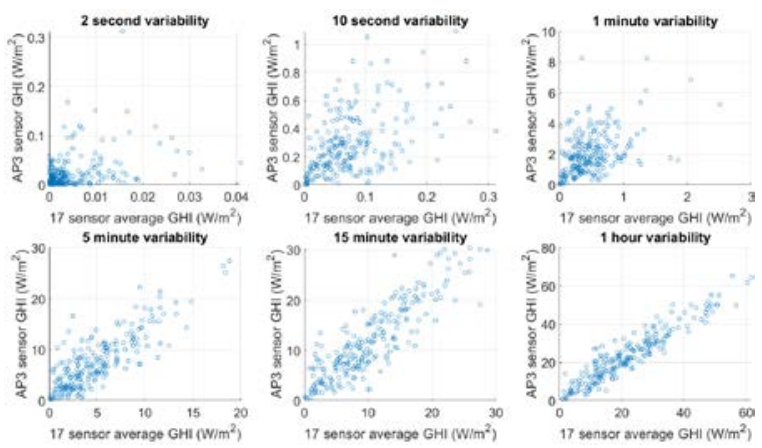

Fig. 1. Variabilities at 6 temporal resolutions obtained from sensor AP3 and average GHI of 17 sensors using the Fourier coefficient metric.
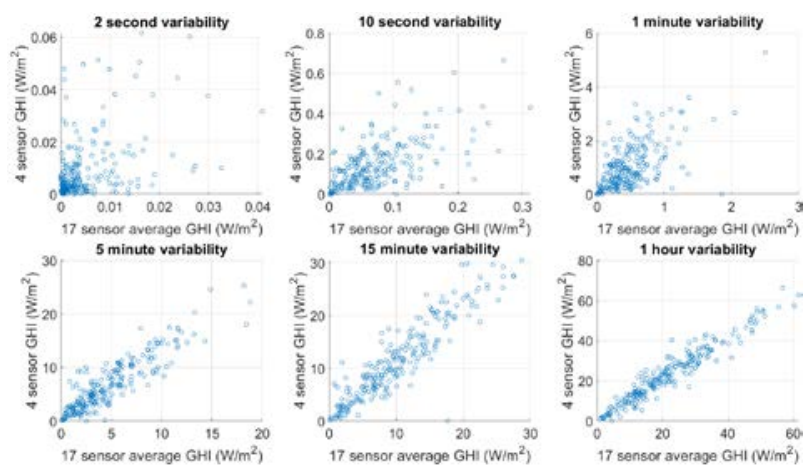

Fig. 2. Variabilities at 6 temporal resolutions obtained from average GHI of 4 sensors and average GHI of 17 sensors using the Fourier coefficient metric.
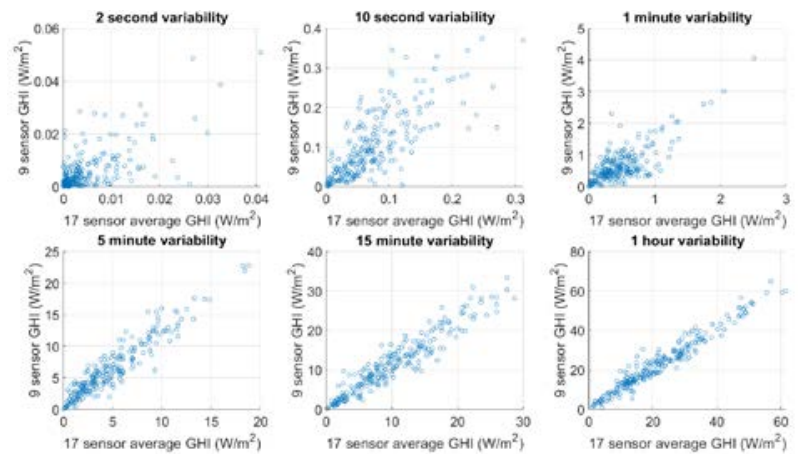

Fig. 3. Variabilities at 6 temporal resolutions obtained from average GHI of 9 sensors and average GHI of 17 sensors using the Fourier coefficient metric.
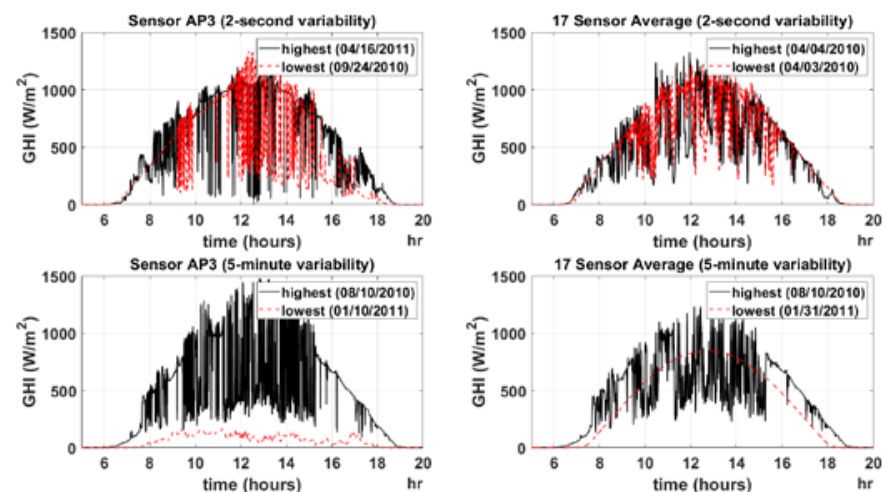

Fig. 4. Plots of GHIs from sensor AP3 and the average GHI of 17 sensors of highest and lowest variability days obtained using the Fourier coefficient metric calculated at 2-second and 5-minute temporal resolutions.
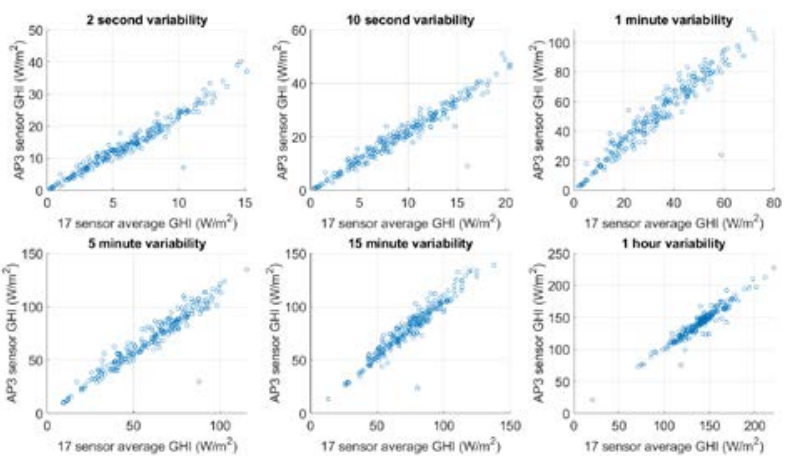

Fig. 5. Variabilities at 6 temporal resolutions obtained from sensor AP3 and average GHI of 17 sensors using the average ramp metric.
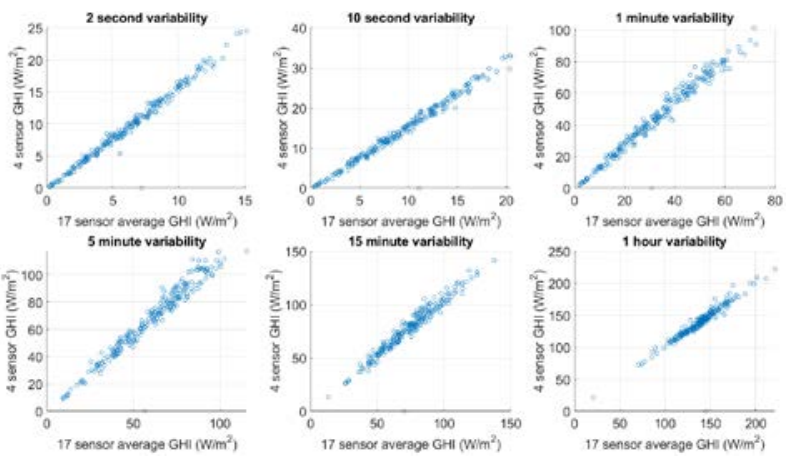

Fig. 6. Variabilities at 6 temporal resolutions obtained from average GHI of 4 sensors and average GHI of 17 sensors using the average ramp metric
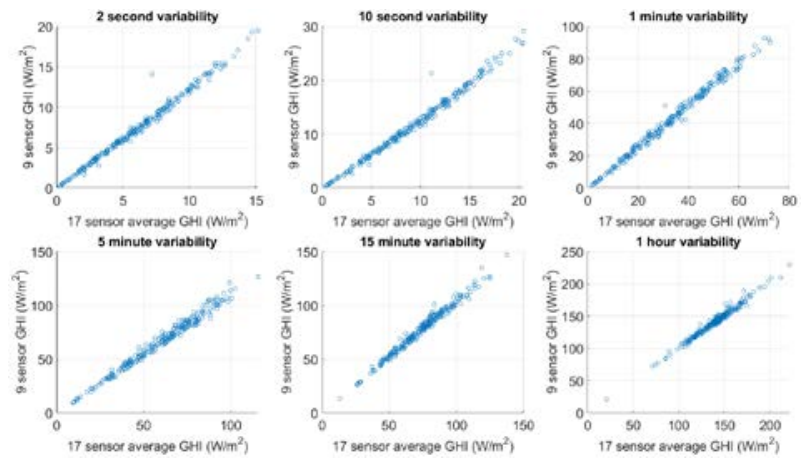

Fig. 7. Variabilities at 6 temporal resolutions obtained from average GHI of 9 sensors and average GHI of 17 sensors using the average ramp metric. 

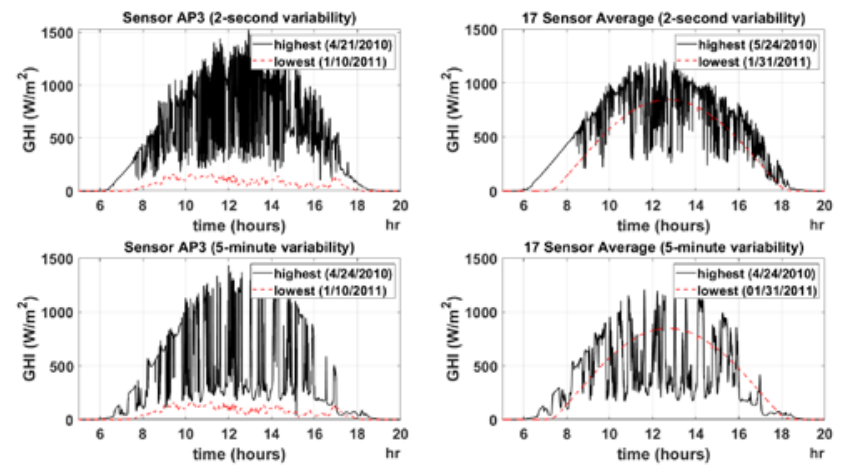

Fig. 8. Plots of GHIs from sensor AP3 and the average GHI of 17 sensors of highest and lowest variability days obtained using the average ramp metric calculated at 2-second and 5-minute temporal resolutions.

TABLE II. MAXIMUM VARIABILITY DAYS FROM FOURIER COEFFICIENT METRIC

\begin{tabular}{|c|c|c|c|c|}
\hline Resolution & $\mathbf{1 ~ s e n s o r}$ & $\mathbf{4}$ sensors & $\mathbf{9}$ sensors & $\mathbf{1 7}$ sensors \\
\hline $2 \mathrm{~s}$ & $04 / 16 / 11$ & $04 / 20 / 10$ & $04 / 04 / 10$ & $04 / 04 / 10$ \\
\hline $10 \mathrm{~s}$ & $04 / 02 / 10$ & $07 / 28 / 11$ & $07 / 15 / 11$ & $07 / 15 / 11$ \\
\hline $1 \mathrm{~min}$ & $03 / 28 / 10$ & $04 / 01 / 10$ & $07 / 21 / 11$ & $05 / 24 / 10$ \\
\hline $5 \mathrm{~min}$ & $08 / 10 / 10$ & $08 / 10 / 10$ & $08 / 10 / 10$ & $08 / 10 / 10$ \\
\hline $15 \mathrm{~min}$ & $05 / 26 / 10$ & $07 / 14 / 11$ & $05 / 26 / 10$ & $05 / 26 / 10$ \\
\hline 1 hour & $07 / 29 / 10$ & $07 / 29 / 10$ & $07 / 29 / 10$ & $07 / 29 / 10$ \\
\hline
\end{tabular}

TABLE III. MINIMUM VARIABILITY DAYS FROM FOURIER COEFFICIENT METRIC

\begin{tabular}{|c|c|c|c|c|}
\hline Resolution & $\mathbf{1}$ sensor & $\mathbf{4}$ sensors & 9 sensors & $\mathbf{1 7}$ sensors \\
\hline $2 \mathrm{~s}$ & $09 / 24 / 10$ & $07 / 21 / 10$ & $09 / 05 / 10$ & $04 / 03 / 10$ \\
\hline $10 \mathrm{~s}$ & $01 / 10 / 11$ & $01 / 10 / 11$ & $01 / 10 / 11$ & $01 / 05 / 11$ \\
\hline $1 \mathrm{~min}$ & $01 / 10 / 11$ & $01 / 10 / 11$ & $01 / 10 / 11$ & $01 / 10 / 11$ \\
\hline $5 \mathrm{~min}$ & $01 / 10 / 11$ & $01 / 31 / 11$ & $01 / 31 / 11$ & $01 / 31 / 11$ \\
\hline $15 \mathrm{~min}$ & $01 / 31 / 11$ & $01 / 31 / 11$ & $01 / 31 / 11$ & $01 / 31 / 11$ \\
\hline 1 hour & $01 / 31 / 11$ & $01 / 31 / 11$ & $01 / 31 / 11$ & $01 / 31 / 11$ \\
\hline
\end{tabular}

TABLE IV. MAXIMUM VARIABILITY DAYS FROM AVERAGE RAMP METRIC

\begin{tabular}{|c|c|c|c|c|}
\hline Resolution & 1 sensor & 4 sensors & 9 sensors & 17 sensors \\
\hline $2 \mathrm{~s}$ & $4 / 21 / 2010$ & $5 / 24 / 2010$ & $5 / 24 / 2010$ & $5 / 24 / 2010$ \\
\hline $10 \mathrm{~s}$ & $4 / 21 / 2010$ & $4 / 2 / 2010$ & $5 / 24 / 2010$ & $7 / 8 / 2011$ \\
\hline $1 \mathrm{~min}$ & $4 / 28 / 2010$ & $4 / 2 / 2010$ & $4 / 28 / 2010$ & $4 / 20 / 2010$ \\
\hline $5 \mathrm{~min}$ & $4 / 24 / 2010$ & $7 / 14 / 2011$ & $4 / 24 / 2010$ & $4 / 24 / 2010$ \\
\hline $15 \mathrm{~min}$ & $7 / 18 / 2010$ & $7 / 18 / 2010$ & $7 / 18 / 2010$ & $7 / 18 / 2010$ \\
\hline 1 hour & $3 / 23 / 2010$ & $3 / 23 / 2010$ & $3 / 23 / 2010$ & $3 / 23 / 2010$ \\
\hline
\end{tabular}

TABLE V. MINIMUM VARIABILITY DAYS FROM AVERAGE RAMP METRIC

\begin{tabular}{|c|c|c|c|c|}
\hline Resolution & $\mathbf{1}$ sensor & $\mathbf{4}$ sensors & $\mathbf{9}$ sensors & $\mathbf{1 7}$ sensors \\
\hline $2 \mathrm{~s}$ & $1 / 10 / 2011$ & $1 / 10 / 2011$ & $1 / 10 / 2011$ & $1 / 31 / 2011$ \\
\hline $10 \mathrm{~s}$ & $1 / 10 / 2011$ & $1 / 31 / 2011$ & $1 / 31 / 2011$ & $1 / 31 / 2011$ \\
\hline $1 \mathrm{~min}$ & $1 / 31 / 2011$ & $1 / 31 / 2011$ & $1 / 31 / 2011$ & $1 / 31 / 2011$ \\
\hline $5 \mathrm{~min}$ & $1 / 10 / 2011$ & $1 / 31 / 2011$ & $1 / 31 / 2011$ & $1 / 31 / 2011$ \\
\hline $15 \mathrm{~min}$ & $1 / 10 / 2011$ & $1 / 10 / 2011$ & $1 / 10 / 2011$ & $1 / 10 / 2011$ \\
\hline 1 hour & $1 / 10 / 2011$ & $1 / 10 / 2011$ & $1 / 10 / 2011$ & $1 / 10 / 2011$ \\
\hline
\end{tabular}

\section{B. Comparison Of Solar Variability Between Stations}

The average ramp metric was used to calculate the solar PV variability for the five single sensor stations listed in Table I. Fourier coefficient metric can also be used, but due to space constraints results using only the ramp metric are presented.

The maximum values of the average ramp metric observed at each of the six stations over the length of the dataset (listed in Table I) for the four variability intervals (1-minute is the highest resolution of these datasets) are listed in Table VI. A very interesting observation from this table is that the maximum ramp sizes at the four temporal resolutions are very similar between the six geographical locations that are very far away from each other. This observation suggests that a reasonable size of the worst solar irradiation ramp can be approximated for various locations from the ramps given in Table VI. After considering other factors that can affect the power plant output such as fixed or tracking axis and shadowing effects, the maximum power ramp at a plant can be approximated and used for power systems studies such as frequency response analysis.

TABLE VI. MAXIMUM AVERAGE RAMPS $\left(\mathrm{W} / \mathrm{m}^{2}\right)$ at 6 LOCATIONS

\begin{tabular}{|c|c|c|c|c|c|}
\hline Station & State & $\mathbf{1 - m i n}$ & $\mathbf{5 - m i n}$ & $\mathbf{1 5}-\mathbf{m i n}$ & $\mathbf{6 0 - m i n}$ \\
\hline Oahu & HI & 60 & 120 & 120 & 240 \\
\hline SolarTAC & CO & 67 & 127 & 135 & 244 \\
\hline $\begin{array}{c}\text { NREL } \\
\text { Station }\end{array}$ & CO & 61 & 120 & 157 & 304 \\
\hline UNLV & NV & 62 & 112 & 132 & 255 \\
\hline UAT & AZ & 91 & 153 & 131 & 255 \\
\hline UTPASRL & TX & 103 & 134 & 136 & 242 \\
\hline
\end{tabular}

\section{Reduction In Solar Variability Over A Region}

While Table VI suggests that maximum average ramp sizes may be similar at 1-minute or lower temporal resolutions between plants located over a large geographical area, it does not provide any information on the expected ramp sizes for the entire region that may have multiple plants (existing or planned). It is well known that decorrelation between the solar ramps at various sites may result in significantly reduced variability over the entire region [4]. It will be ideal if a relation between the solar PV variability of one plant vs the combined variability of all the plants over a large region (e.g., utility footprint) can be obtained. This will allow planners to consider the impacts of variability of solar PV for future PV installations by knowing the variability of an existing plant or that observed at an existing sensor. To this end, we tried to estimate how the 
variability of a single sensor at NREL Station and solarTAC compared with the combined variability of the two sensors. These two sensors are located about $50 \mathrm{~km}$ apart. Ideally, solar PV output of multiple sensors within $50 \mathrm{~km}$ radius should have been used to get more definitive results, but good quality, highresolution data was not available.

Table VII shows twice the maximum of the average ramp metric (multiplication by 2 was done to reflect the assumption of perfect correlation between the two locations) calculated over the entire length of the dataset for the individual stations and maximum of the average ramp metric for the combined output of the two stations. The ramp size of the combined output is smaller by at least $13 \%$ over all the temporal resolutions compared with the case if the solar GHIs were completely correlated. On average, the variability reduction is $24 \%, 30 \%, 32 \%$, and $22 \%$ for the combined output for $1,5,15$, and 60-minute time resolutions, respectively. The available dataset is too small and variations in reductions in variability between the combined output and the outputs of individual sites too large to come to any definitive conclusion regarding the percentage decrease in sizes of ramps compared to the ramps of individual plants when multiple solar plants over a radius of 50 $\mathrm{km}$ are combined. Nonetheless, this analysis does indicate that significant reduction in variability of the combined output of multiple plants spread over a region can be expected and the reduction can be quantified if more high quality, high resolution solar irradiation measurements are available from multiple locations in a region.

TABLE VII. COMPARISON OF RAMPS $\left(W / m^{2}\right)$ FROM SOLARTAC, NREL STATION, AND THE COMBINED OUTPUT OF THESE TWO STATIONS

\begin{tabular}{|c|c|c|c|c|}
\hline Station & 1-min & 5-min & 15-min & 60-min \\
\hline Combined & 97 & 173 & 198 & 423 \\
\hline NREL Station & 122 & 240 & 314 & 608 \\
\hline SolarTAC & 134 & 254 & 270 & 488 \\
\hline $\begin{array}{c}\text { \% reduction in } \\
\text { combined w.r.t NREL } \\
\text { Station }\end{array}$ & $20 \%$ & $28 \%$ & $37 \%$ & $30 \%$ \\
\hline $\begin{array}{c}\text { \% reduction in } \\
\text { combined w.r.t } \\
\text { solarTAC }\end{array}$ & $28 \%$ & $32 \%$ & $27 \%$ & $13 \%$ \\
\hline
\end{tabular}

\section{CONCLUSION}

This paper attempted to quantify solar PV plant variabilities at various temporal resolutions ranging from seconds to an hour. Considering the challenges in obtaining analytical expressions to quantify high temporal resolution solar PV plant output variabilities, a data-based approach was used to quantify the variability. The three key takeaways from the presented work for power systems studies under high solar PV penetration, particularly for frequency response studies that require seconds level temporal resolution data are:

- Use multiple sensors spread over a plant (or over the site of a future plant) to estimate the variability that may occur at seconds-level temporal resolutions. Even a cluster of few appropriately placed sensors may provide significantly better results than a point sensor.
- The largest solar irradiation ramps at an existing solar PV plant or at a future plant location at 1-minute and lower temporal resolutions may be approximated by the largest ramps observed at existing sensors in the region, which do not need to be in proximity of the plant.

- High quality and high spatial density solar irradiation datasets with seconds-level temporal resolution should be created because few such datasets are publicly available today and their value cannot be overstated for modeling solar PV plant variability in frequency response studies.

The observations and findings from this work can be used as the foundation for more extensive solar PV plant variability analysis using high quality, high resolution data. The solar PV irradiation data can also be converted into real power output data by considering the location, orientation, fixed or tracking axis technology, and shading effects using tools such as the System Advisor Model (SAM) [20]. As more high quality and high temporal resolution solar PV irradiation data becomes available, the analysis presented in the paper can be used to evaluate expected solar variability for grid study under very high solar PV penetration, which can be of significant value to power system operators and planners for evaluating the reliability of power systems.

\section{REFERENCES}

[1] P. A. Jimenez et al., "WRF-Solar: Description and Clear-Sky Assessment of an Augmented NWP Model for Solar Power Prediction," Bull. Amer. Meteor. Soc., vol. 97, no. 7, pp. 1249-1264, Jul. 2016, doi: 10.1175/BAMS-D-14-00279.1.

[2] J. Munkhammar and J. Widén, "An autocorrelation-based copula model for generating realistic clear-sky index time-series," Solar Energy, vol. 158, pp. 9-19, Dec. 2017, doi: 10.1016/j.solener.2017.09.028.

[3] C. A. Glasbey, R. Graham, and A. G. M. Hunter, "Spatio-temporal variability of solar energy across a region: a statistical modelling approach," Solar Energy, vol. 70, no. 4, pp. 373-381, Jan. 2001, doi: 10.1016/S0038-092X(00)00152-3.

[4] A. Mills et al., "Dark Shadows," IEEE Power and Energy Magazine, vol. 9, no. 3, pp. 33-41, May 2011, doi: 10.1109/MPE.2011.940575.

[5] L. M. Hinkelman, "Differences between along-wind and cross-wind solar irradiance variability on small spatial scales," Solar Energy, vol. 88, pp. 192-203, Feb. 2013, doi: 10.1016/j.solener.2012.11.011.

[6] J. Munkhammar, J. Widén, and L. M. Hinkelman, "A copula method for simulating correlated instantaneous solar irradiance in spatial networks," Solar Energy, vol. 143, pp. 10-21, Feb. 2017, doi: 10.1016/j.solener.2016.12.022.

[7] Matthew Lave, Abraham Ellis, and Joshua S. Stein, "Simulating Solar Power Plant Variability: A Review of Current Methods," Sandia National Laboratories, SAND2013-4757, Jun. 2013.

[8] H. Moaveni, D. K. Click, R. H. Meeker, R. M. Reedy, and A. Pappalardo, "Quantifying solar power variability for a large central PV plant and small distributed PV plant," in 2013 IEEE 39th Photovoltaic Specialists Conference (PVSC), Jun. 2013, pp. 0969-0972, doi: 10.1109/PVSC.2013.6744303.

[9] A. Kumler, I. L. Carreño, M. T. Craig, B.-M. Hodge, W. Cole, and C. Brancucci, "Inter-annual variability of wind and solar electricity generation and capacity values in Texas," Environ. Res. Lett., vol. 14, no. 4, p. 044032, Apr. 2019, doi: 10.1088/1748-9326/aaf935.

[10] J. Tan and Y. Zhang, "Coordinated Control Strategy of a Battery Energy Storage System to Support a Wind Power Plant Providing MultiTimescale Frequency Ancillary Services," IEEE Transactions on Sustainable Energy, vol. 8, no. 3, pp. 1140-1153, Jul. 2017, doi: 10.1109/TSTE.2017.2663334. 
[11] North American Reliability Corporation, Standard BAL-001-2 - Real Power Balancing Control Performance, vol. BAL-001-2. .

[12] "NREL: Measurement and Instrumentation Data Center (MIDC) Home Page." https://midcdmz.nrel.gov/ (accessed Jun. 29, 2019).

[13] M. Sengupta and A. Andreas, "Oahu Solar Measurement Grid (1-Year Archive): 1-Second Solar Irradiance; Oahu, Hawaii (Data)," National Renewable Energy Laboratory, DA-5500-56506, 2010. [Online]. Available: http://dx.doi.org/10.5439/1052451.

[14] A. Andreas and S. Wilcox, "Solar Technology Acceleration Center (SolarTAC); Aurora, Colorado (Data)," National Renewable Energy Laboratory, DA-5500-56491, 2011. [Online]. Available: http://dx.doi.org/10.5439/1052224.

[15] A. Andreas and T. Stoffel, "NREL Solar Radiation Research Laboratory (SRRL): Baseline Measurement System (BMS); Golden, Colorado (Data)," National Renewable Energy Laboratory, DA-5500-56488, 1981. [Online]. Available: http://dx.doi.org/10.5439/1052221.

[16] A. Andreas and T. Stoffel, "University of Nevada (UNLV): Las Vegas, Nevada (Data)," National Renewable Energy Laboratory, DA-550056509, 2006. [Online]. Available: http://dx.doi.org/10.5439/1052548.

[17] A. Andreas and S. Wilcox, "Observed Atmospheric and Solar Information System (OASIS); Tucson, Arizona (Data)," National Renewable Energy Laboratory, DA-5500-56494, 2010. [Online]. Available: http://dx.doi.org/10.5439/1052226.

[18] J. Ramos and A. Andreas, "University of Texas Panamerican (UTPA): Solar Radiation Lab (SRL); Edinburg, Texas (Data)," National Renewable Energy Laboratory, DA-5500-56514, 2011. [Online]. Available: http://dx.doi.org/10.5439/1052555.

[19] D. Yang, "Ultra-fast preselection in lasso-type spatio-temporal solar forecasting problems," Solar Energy, vol. 176, pp. 788-796, Dec. 2018, doi: 10.1016/j.solener.2018.08.041.

[20] "System Advisor Model (SAM) |." https://sam.nrel.gov/ (accessed Mar. 14, 2019). 